\title{
Análise do Comportamento Decisório de Analistas Contábil- Financeiros: um estudo com base na Teoria da Racionalidade Limitada
}

Analyzing the Decision-Making Behavior of Finance-Accounting Analysts: a study based on the Bounded Rationality Theory

\section{Marcelo Alvaro da Silva Macedo}

Doutor em Engenharia de Produção na COPPE pela Universidade Federal do Rio de Janeiro Professor do Mestrado em Ciências Contábeis da FACC - Universidade Federal do Rio de Janeiro

Endereço: Depto. de Contabilidade - FACC - UFRJ

Av. Pasteur, 250 - Urca

CEP: 22.290-902 - Rio de Janeiro/RJ

E-mail: malvaro.facc.ufrj@gmail.com

Telefone: (21) 9765-6553

\section{Patrícia Vivas da Silva Fontes}

Graduada em Economia pela Universidade Federal Rural do Rio de Janeiro

Endereço: DCAC/ICHS/UFRRJ

Rodovia BR 465, Km 07

CEP: 23.890-000 - Seropedica/RJ

E-mail: patybj_16@hotmail.com ou patybj_16@yahoo.com.br

Telefone: (21) 2682-1042

Artigo recebido em março de 2009. Passou por uma avaliação double blind review em agosto de 2009. Aceito em novembro de 2009 pela Editora Científica Sandra Rolim Ensslin. Artigo apresentado no XXXII Encontro da ANPAD (EnANPAD), 2008, Rio de Janeiro, 2008. 


\title{
Resumo
}

Este estudo procura analisar o impacto da racionalidade limitada no processo decisório, num ambiente de análise contábil-financeira. Para tanto, foi aplicado um questionário a 91 analistas, que eram convidados a tomar uma decisão ou emitir uma opinião acerca dos aspectos abordados em cada uma das questões. Os resultados mostram que, de maneira geral, no caso dos analistas da amostra, o uso das heurísticas de julgamento, bem como da teoria dos prospectos, levam a vieses, que desviam a escolha de uma alternativa meramente racional.

Palavras-chave: Racionalidade Limitada, Heurísticas de Julgamento, Teoria Prospectiva, Vieses de Decisão.

\begin{abstract}
This study analyzes the impact of bounded rationality on the decision-making process in an environment of finance-accounting analysis. To accomplish this goal, a questionnaire was given to 91 analysts, who were required to make a decision or give their opinion about issues addressed in each question. The results indicate that, in general, in the case of the analysts in this sample, the use of judgment heuristics and of prospect theory lead to decision biases that prevent them from choosing a purely rational alternative.
\end{abstract}

Key words: Bounded Rationality, Judgment Heuristics, Prospective Theory, Decision Biases.

\section{Introdução}

Segundo Oliveira e Alperstedt (2003), até pouco tempo, a teoria gerencial apoiava-se na premissa de que bastava coletar grande quantidade de informações e processá-las conforme critérios de racionalidade para determinar os destinos da organização. Mas agora, na realidade empresarial, há a necessidade de se tomarem decisões críticas cada vez mais frequentes diante das mudanças rápidas e radicais do mundo atual. Assim, com o objetivo de melhorar o processo decisório, cientistas têm analisado com crescente profundidade os processos mentais que $o$ homem utiliza para decidir.

Dessa forma, de acordo com Barreiros et al. (2005), a abordagem racional das tomadas de decisão apresentou diversas dificuldades e inconsistências na medida em que outras dimensões do indivíduo organizacional passaram a serem consideradas, tais como comportamentais, políticas, sociais e ambientais. Todas estas restringem o alcance do "ideal de racionalidade" da teoria econômica neoclássica.

Segundo Souza et al. (2006), a questão é que nem sempre o processo de escolha na tomada de decisão é simples. Uma maneira de simplificar esse processo é admitir a existência da racionalidade limitada, proposta por Simon (1957), na qual somente aqueles fatores que estão estreitamente ligados, casual e temporalmente, com a decisão podem ser levados em consideração (SIMON, 1955).

Bazerman (2001) aponta que o campo da tomada de decisão pode ser, em linhas gerais, dividido em duas partes: o estudo dos modelos prescritivos (ou nor- 
mativos) e aquele dos modelos descritivos. Os modelos prescritivos ocupam-se da prescrição de métodos para a tomada de decisão ótima (utilização de ferramentas para auxílio no processo de tomada de decisão), enquanto os modelos descritivos estão preocupados com a forma limitada pela qual as decisões são efetivamente tomadas.

Neste trabalho, daremos maior ênfase e atenção às questões pertinentes aos modelos descritivos. A motivação para esse tipo de abordagem se dá pelo fato de que, considerando que os tomadores de decisão decidem centenas de vezes a cada dia, não são viáveis as exigências sistemáticas e demoradas do processo "racional" de tomada de decisão. A maioria das decisões é feita por julgamentos, em vez de um modelo prescritivo definido.

É nesse sentido que se propõe este trabalho, onde se estuda o processo de tomada de decisão como uma resultante de uma série de variáveis comportamentais, ou seja, o intuito deste artigo é exatamente discutir a problemática do processo decisório e de seus aspectos cognitivos num ambiente empresarial. Trata-se, nesta pesquisa, de vários elementos críticos para o desenvolvimento da capacidade gerencial de tomar decisões eficazes e de avaliar devidamente as decisões dos outros. Sendo assim, a questão de pesquisa central é: Existe impacto dos aspectos cognitivos do processo decisório na área contábil-financeira? $\mathrm{Ou}$ seja, os analistas contábil-financeiros usam as heurísticas de julgamento e a teoria dos prospectos em seus processos decisórios, e isso leva a ocorrência de vieses de decisão?

O objetivo deste artigo é, então, por meio de uma análise do comportamento decisório de analistas contábil-financeiros, promover a discussão e o reconhecimento de que sistematicamente desviam-se as decisões de um comportamento puramente racional, em virtude do uso de heurísticas de julgamento e da teoria dos prospectos, que, em muitos casos, levam a vieses de decisão. Em síntese, analisa-se o comportamento decisório de analistas contábil-financeiros, verificando o impacto do uso das heurísticas de julgamento e da teoria dos prospectos, pela verificação da ocorrência dos vários vieses de decisão oriundos delas.

\section{Referencial Teórico}

\subsection{Racionalidade Limitada: aspetos fundamentais}

Bazerman (2001) afirma que um processo decisório sob a perspectiva "racional" propicia uma orientação baseada em um conjunto de suposições, para se pensar sobre como seria um processo ótimo de tomada de decisão, sem considerar explicitamente como uma decisão é tomada. 
Porém, Andrade et al. (2007) enfatizam que os conceitos de racionalidade limitada, por meio da busca por uma solução satisfatória em vez de ótima, são relevantes para verificar se o comportamento decisório se desvia da racionalidade pura, já que identificam situações nas quais os tomadores de decisão podem estar agindo com base em informações restritas, condicionados pelo fato de que a capacidade da mente humana para formular e solucionar problemas complexos é muito pequena comparada à necessidade para uma decisão racional e estruturada, que levam aos vieses específicos, sistemáticos e direcionais.

Para Carvalho et al. (1999), a teoria cognitiva emerge como contraponto à concepção racionalista da ação, já que os seres humanos não podem processar todos os dados sensoriais num cálculo racional, senão que fazem uso e formam conceitos que, baseados em suas experiências anteriores, os ajudam a tomar decisões.

Nesse sentido, de acordo com Yoshinaga et al. (2004), a Psicologia oferece o aparato teórico que possibilita entender os vieses cognitivos que influenciam o comportamento, desviando-o da racionalidade pura, e a Sociologia se estrutura no aparato institucional, dando lugar aos elementos subjetivos do conhecimento humano.

Cabe ressaltar, neste ponto, os aspetos relacionados ao processo decisório, advindos da Teoria Institucional. De acordo com Guerreiro et al. (2004), existe um aparente paradoxo entre a adoção de técnicas e procedimentos à disposição dos gestores empresariais e o dia a dia do processo de tomada de decisão. Isso acontece, segundo Aguiar e Guerreiro (2007), pela tendência do uso de caminhos mais "conhecidos e familiares" em vez da implementação de mudanças, que, mesmo que tecnicamente melhores, não são adotadas. Isso é uma explicação, com base na Teoria Institucional, para o uso de heurísticas de julgamento e da teoria dos prospectos, por exemplo.

Para Branco (2006) e Carvalho et al. (1999), a abordagem institucionalista vê as instituições como determinantes fundamentais do comportamento dos agentes e como resultado do comportamento dos indivíduos em sociedade, destacando-se, dessa forma, a presença de elementos culturais. Assim, a consequência desse novo marco na interpretação organizacional revela que todo o entendimento estabelecido sobre a racionalidade, no atual ambiente organizacional, precisa ser limitado por esses elementos.

Segundo Prates e Sobreira (2004), baseados no princípio da racionalidade limitada, defendida por Simon (1957), é possível perceber que os tomadores de decisão em ambientes organizacionais, regularmente, perdem algumas informações importantes durante o processo de tomada de decisão. Dessa forma, a escolha final nem sempre recai sobre a melhor alternativa possível, mas, sim, sobre a primeira alternativa encontrada que satisfaça as expectativas do tomador de decisão. 
Kahneman e Tversky (1979), baseados na noção de racionalidade limitada de Simon (1957), abriram caminho, por meio de sua pesquisa, para a avaliação da influência de aspectos psicológicos no processo de decisão contábil-financeira. Os estudos subsequentes discutiram esta temática pela Contabilidade Comportamental e pelas Finanças Comportamentais. Estas ganharam grande destaque em função, principalmente, de imaginar-se que os decisores destas áreas não seriam expostos a essa problemática, já que seriam mais propensos a usar uma sistemática meramente racional.

Segundo Kimura (2003), as Finanças Comportamentais representam um novo ramo na Teoria Financeira que busca incorporar os aspectos sociológicos e psicológicos no processo de análise, partindo do reconhecimento de que investidores e analistas nem sempre se comportam de forma racional. Ou seja, de acordo com Halfeld e Torres (2001), as Finanças Comportamentais têm como objetivo a revisão e o aperfeiçoamento do modelo de decisão econômico-financeiro pela incorporação dos aspectos da racionalidade limitada.

Nesse contexto, segundo Shleifer (2000), surge a hipótese das finanças comportamentais como forma alternativa de avaliação do mercado, que sugere que, ao contrário das hipóteses de eficiência, devem-se esperar desvios significativos e sistemáticos em relação aos valores esperados pela aplicação da racionalidade econômica.

Já a temática sobre Contabilidade Comportamental teve um grande impulso, segundo Birnberg et al. (1998), nos trabalhos de Ashton e Ashton (1995) e Arnold e Sutton (1997), sobre julgamento e tomada de decisão em Contabilidade e Auditoria.

Esta passou a ser uma importante área de estudos das Ciências Contábeis, pois, de acordo com Williams et al. (2006), como a Contabilidade é uma atividade construída com base em valores humanos, torna-se imprescindível analisar o impacto das questões cognitivas, inerente ao ser humano sobre a prática contábil. Por conta disso, passou a ser relevante as contribuições que outras ciências do comportamento, tais como a Psicologia e a Sociologia, podem aportar nesse sentido. Sendo assim, a Contabilidade Comportamental pode ser vista, então, segundo Presutti Jr. (1995), como a aplicação de outras ciências do comportamento para explicar fenômenos contábeis e solucionar problemas práticos.

Uma das ideias fundamentais para a Contabilidade Comportamental e para as finanças comportamentais é a Teoria dos Prospectos. Conforme Kimura e Basso (2003) destacam, essa teoria representa uma leitura avançada do processo de tomada de decisão em condições de risco. Esta permite identificar comportamentos diferenciados frente a perdas e ganhos do investidor, explicados por possíveis sobre ou sub-reações de mercado, decorrente dos vieses de julgamento aos quais os investidores estão expostos. 
Na Teoria dos Prospectos, conforme enfatizam Andrade et al. (2007), os resultados são vistos como desvios em relação ao referencial adotado na tomada de decisão. Em suma, diz-se que se os resultados são vistos como ganhos, prevalece uma posição de aversão ao risco; se forem vistos como perdas, prevalece, então, a propensão ao risco. Isso, segundo Kahneman et al. (1988), evidencia a existência do "efeito framing".

Para Kahneman e Tversky (1979), a influência da estruturação dos prospectos nas escolhas (efeito framing) evidencia que a simples formulação das alternativas faz com que as pessoas tenham comportamentos opostos em relação a preferências por prospectos. Isso indica a quebra da suposição de que as decisões são determinadas somente pelas probabilidades dos possíveis resultados finais dos prospectos. Desvia-se, portanto, das teorias do valor esperado e da utilidade esperada, que afirmam que o decisor deveria ser imune ao enquadramento de informações, levando-os sempre a decisões conscientes e plenamente racionais (MACEDO et al.,2007a).

\subsection{Heurísticas de Julgamento e Vieses de Decisão}

De acordo com Luppe et al. (2007), citando os estudos de Simon (1957), os tomadores de decisão têm limitações em suas habilidades no processo de obtenção e tratamento das informações. Consequentemente, eles não decidem de modo inteiramente racional. Por isso, argumenta Bazerman (2001), valem-se de "regras práticas" ou heurísticas para tomar decisões, tendo por base que os benefícios de tempo economizado, na busca e análise de informações, frequentemente são maiores do que os custos de qualquer redução potencial na qualidade da decisão.

Assim sendo, as Heurísticas de Julgamento podem ser definidas, de acordo com Tversky e Kahneman (1974) e Andrade et al. (2007), como uma série de estratégias simplificadoras em que as pessoas se baseiam ao tomarem decisões. Estas consistem em regras-padrão que implicitamente dirigem o comportamento decisório e servem como um mecanismo para se lidar com o ambiente complexo que cerca as decisões. São identificados três grupos genéricos de heurísticas: da Disponibilidade; da Representatividade; e da Ancoragem e Ajustamento.

A Heurística da Disponibilidade consiste em reconhecer a possibilidade de um acontecimento comparando-o com aqueles que estão dispostos na memória (TVERSKY e KAHNEMAN, 1973). Em outras palavras, existem situações nas quais as pessoas avaliam a frequência ou a probabilidade de um evento pela facilidade com que as ocorrências podem ser trazidas à mente (KAHNEMAN et al., 1988).

Segundo Ciarelli e Ávila (2005), a regra da disponibilidade é um guia 
útil para a estimação de frequências ou probabilidades, porque exemplos de grupos grandes são geralmente alcançados de maneira melhor e mais rápida do que exemplos de grupos menores, de forma que esta heurística leva geralmente a um julgamento acurado (BAZERMAN, 2001). Todavia, a facilidade com que os pensamentos e exemplos vêm à mente é afetada também por fatores diversos de sua frequência e probabilidade. Como descreve Bazerman (2001), um evento que evoca emoções é vívido, facilmente imaginado e específico será mais disponível do que um evento que é não emocional em sua natureza, insípido, difícil de imaginar ou vago. Outro fator importante que pode distorcer a disponibilidade de um exemplo na memória é a superexposição de um indivíduo a determinada situação - como uma veiculação massiva de determinados eventos ou circunstâncias na mídia (BAZERMAN, 2001).

A Heurística da Representatividade acontece quando comparamos a probabilidade de um acontecimento com categorias semelhantes preexistentes. Segundo Kimura e Basso (2003), a representatividade é uma heurística que se refere ao julgamento baseado em estereótipos. No caso de investimentos, a Heurística da Representatividade pode influenciar a percepção dos investidores sobre o potencial de valorização de uma ação. Investidores podem avaliar positivamente o potencial de uma ação específica simplesmente em função de terem formado uma opinião estereotipada sobre a empresa.

Segundo Prates e Sobreira (2004), na representatividade, as expectativas não são formadas com base na probabilidade de cada evento, mas, sim, do quão representativo esse evento é de sua população. A utilização dessa ferramenta, continuam os autores, induz a uma série de erros de estimação, uma vez que ela não está sujeita a diversos fatores que afetam as estimativas construídas pelo uso do conceito probabilístico.

Por fim, a Heurística da Ancoragem e Ajustamento ocorre quando uma pessoa, no processo decisório, se vale de um valor de referência (âncora) para escolher um determinado rumo de ação e ajusta esse valor para chegar a uma decisão final (ajustamento).

De acordo com Prates e Sobreira (2004), esse efeito consiste na elaboração de previsões com relação a uma determinada variável por meio de um processo de ajuste de valores previamente estabelecidos como ponto de partida. Nesse caso, as previsões estariam sempre enviesadas, uma vez que pontos de partida diferentes levariam a previsões diferentes. Ainda para os autores, nos ajustes de preços em mercados de ações, os investidores tendem a utilizar o preço do dia anterior como âncora, e a partir dele efetuar ajustes.

Tendo em vista todas as heurísticas apresentadas, além das questões relacionadas à teoria dos prospectos, destacam-se alguns vieses de decisão oriundos do uso destas, segundo Andrade et al. (2007), que, no Quadro 1, são analisadas 
no estudo empírico aqui conduzido:

\section{Quadro 1: Vieses de Decisão}

\begin{tabular}{|c|c|}
\hline Viés & Descrição \\
\hline Falta de Sensibilidade às Proporções da Base & $\begin{array}{l}\text { este viés se refere à situação em que o individuotende a ignorar dados e fatos relevantes } \\
\text { passando a considerar informações irrelevantes ao processo decisório. }\end{array}$ \\
\hline $\begin{array}{l}\text { Falta de Sensibilidade ao tamanho da } \\
\text { amostra }\end{array}$ & $\begin{array}{l}\text { este ocorre quando o indivíduo ignora o tamanho da amostra; crítica para uma avaliação } \\
\text { estatística rigorosa, crucial para a decisão. }\end{array}$ \\
\hline Concepções Errôneas do acaso & $\begin{array}{l}\text { referência ao fato de que as pessoas ignoram a independência de eventos múltiplo } \\
\text { aleatórios, em vista de procurarem eventos que se pareçam mais aleatórios, fazendo uso } \\
\text { errado da intuição e da heurística da representatividade decidindo por determinados } \\
\text { desempenhos pouco prováveis. }\end{array}$ \\
\hline A Falácia da Conjunção & $\begin{array}{l}\text { refere a uma das leis qualitativas mais simples e fundamentais da probabilidade, caso em que } \\
\text { um subconjunto não pode ser mais provável do que um conjunto maior que incluitotalmente } \\
\text { primeiro. A conjunção será julgada mais provável do que um componente isolado, ou seja, } \\
\text { um evento que é formado pela conjunção de dois outros eventos tem uma probabilidade } \\
\text { menor de ocorrência do que cada um dos eventos isolados, mas será considerada mais } \\
\text { representativa. }\end{array}$ \\
\hline $\begin{array}{l}\text { Decisões Afetadas pelo Enquadramento das } \\
\text { Escolhas }\end{array}$ & $\begin{array}{l}\text { este viés reflete, com maior incidência, sobre a soma dos resultados de todas as escolhas } \\
\text { indesejáveis predominando sobre a soma de todas as escolhas desejáveis, isto é, } \\
\text { enquadramento do problema é combinado em duas partes, tendo como resultado uma } \\
\text { reversão de preferências. Na realidade, esta inconsistência viola os requisitos fundamentais } \\
\text { da tomada de decisão racional, consistência e coerência. }\end{array}$ \\
\hline $\begin{array}{l}\text { Decisões Afetadas pelo Enquadramento dos } \\
\text { Resultados }\end{array}$ & $\begin{array}{l}\text { aqui a localização do referencial é construída para se determinar que uma decisão está } \\
\text { enquadrada positivamente ou negativamente, afetando a preferência do risco resultante do } \\
\text { tomador de decisão. }\end{array}$ \\
\hline $\begin{array}{l}\text { Decisões Afetadas pela Pseudocerteza e } \\
\text { Pseudo-incerteza Enquadradas nas Escolhas }\end{array}$ & $\begin{array}{l}\text { relacionado ao fato dos indivíduos darem menor peso a eventos de alta probabilidade, mas } \\
\text { ponderarem adequadamente eventos que são certos. Aqui, a inconsistência de julgamento é } \\
\text { observada, pela facilidade de manipulação da percepção de certeza, originando o efeito } \\
\text { certeza e o efeito pseudocerteza. }\end{array}$ \\
\hline $\begin{array}{l}\text { Enquadramento do Pagamento de Prêmios } \\
\text { versus a Aceitação de Perdas Certas }\end{array}$ & $\begin{array}{l}\text { neste viés se verifica que as pessoas estão mais propensas a aceitarem uma perda certa se } \\
\text { tal for vista como o prêmio de um seguro do que se encarada como um prejuízo financeiro. }\end{array}$ \\
\hline
\end{tabular}

Fonte: Andrade et al. (2007).

\subsection{Evidências Empíricas sobre a Racionalidade Limitada}

Há um extenso material de evidência empírica que comprovam a Teoria de Prospecto e que constitui a base de finanças comportamentais. Como a replicação dos estudos realizados por Kahneman e Tversky (1979), e Kimura e Basso (2003) dentro contexto brasileiro, que sugere que os aspectos comportamentais na tomada de decisão mantêm-se ao longo do tempo e são pouco influenciados por possíveis vieses culturais.

Os estudos realizados por Kimura (2003) permitem identificar que fatores comportamentais dos investidores podem influenciar, de modo irracional, nos preços dos ativos financeiros. Os resultados apontam para consistentes sub-reações de mercado quando os retornos não são ajustados pelo nível de risco. Da mesma forma, Fonte Neto e Carmona (2006) constataram que, para a maior parte dos casos, o mercado tem reagido com velocidade e de maneira consistente apenas nas más notícias macroeconômicas, característica esta que pode ser interpretada como um possível viés comportamental, excesso de pessimismo. 
Podem-se encontrar também diversos experimentos que comprovam a existência de heurísticas e vieses comportamentais. Em suas pesquisas, Macedo et al. (2007a e 2007b) procuram mostrar como as pessoas são afetadas pelo uso de heurísticas de julgamento, pela ocorrência dos vieses de decisão.

Macedo et al. (2007a) afirmam que 121 profissionais ligados aos cursos de graduação em Administração (professores, coordenadores, diretores, etc.), no Brasil, responderam a um questionário com três perguntas, onde eram convidados a tomar uma decisão ou emitir uma opinião acerca dos aspectos abordados em cada uma das questões. Já em Macedo et al. (2007b), 60 pequenos empresários do Rio de Janeiro responderam a um questionário com cinco perguntas nos moldes da outra pesquisa.

Os resultados de ambos os estudos mostraram que os respondentes utilizam heurísticas de julgamento, especificamente da representatividade e da disponibilidade, que levam a vieses de decisão, tais como a falácia da conjunção, a concepção errônea do acaso e a independência entre eventos. Além disso, observou-se apenas no primeiro estudo o impacto da teoria dos prospectos em uma situação de diferenciação no enquadramento da informação (efeito framing).

$\mathrm{O}$ efeito framing também foi confirmado no estudo de Cardoso et al. (2007), que observaram o mesmo efeito, em relação a decisões individuais baseadas em informações contábeis no Brasil, num grupo de 120 estudantes de graduação e pós-graduação em Administração. Nessa mesma linha, o trabalho de Steiner Neto et al. (1998) verificou a consistência do comportamento do decisor perante o risco, pela análise feita por 225 executivos de empresas de Curitiba. Os resultados mostram que, em situações semelhantes, tomadores de decisão tendem a mostrar comportamento inconsistente para decisões que envolvem diferentes tipos de beneficiários.

Já Ávila e Costa (1996) aplicaram um questionário com 10 perguntas abordando, dentre outras questões, o efeito framing a uma amostra de 175 pessoas, sendo 87 alunos de graduação de Administração ou de Economia (menos experientes) e outros 88 alunos de Especialização em Gestão (mais experientes). Os resultados também confirmaram o efeito framing, e este não desapareceu em função da experiência dos respondentes.

$\mathrm{O}$ artigo de Steiner Neto et al. (2000) analisou o comportamento de 37 profissionais das áreas de administração de fundos de quatro instituições financeiras. Os resultados, na amostra estudada, indicam uma possível deficiência dos respondentes em valorar as situações com que se deparam, em ponderar os valores em questão, além de apresentarem maior dificuldade em lidar com a perda.

Já Prates e Sobreira (2004) analisaram os instrumentos da heurística da representatividade, no contexto de decisão em mercados financeiros, com base nos testes desenvolvidos por Kahneman e Tversky (1979), de forma a comparar como 
seria a reação de seu grupo em relação ao grupo original. A conclusão obtida foi que, para alguns elementos específicos da representatividade, existem diferenças que precisam ser consideradas.

Pode-se também identificar resultados empíricos em diversas publicações que analisam como os indivíduos processam e avaliam informações de modo a estabelecer escolhas. Para Barreiros et al. (2005), o nível de racionalidade aplicado no processo decisório está ligado à probabilidade de adequação de acertos. A partir disso, adotou um modelo de racionalidade limitada para analisar o processo decisório em nível estratégico em cooperativas. Os resultados apontaram que prevalece o modelo de racionalidade limitada e que a dimensão da racionalidade é maior durante a fase de posicionamento das cooperativas no mercado, se comparados com a fase de organização dos cooperados. Já Decourt e Accorsi (2005) buscaram explicar as contradições dos pressupostos da racionalidade, por meio de um experimento simulando algumas decisões financeiras para dois grupos: um com e outro sem conhecimentos de mercado. Os resultados mostraram que ambos os grupos têm sua racionalidade afetada por aspectos psicológicos.

Em sua pesquisa, Louback et al. (2007) realizaram um estudo multicaso para analisar racionalidades no âmbito de organizações do Terceiro Setor. $\mathrm{O}$ estudo revelou que os valores organizacionais guardam íntima relação com a orientação das organizações por racionalidades instrumental ou substantiva.

Oliveira e Alperstedt (2003) analisaram as decisões estratégicas de uma empresa de papel e a interferência da intuição na base dessas decisões. Os resultados mostraram que a racionalidade econômica e a busca incessante pela tomada de decisões mais acertadas podem obscurecer as visões tão perseguidas pelos estrategistas, já que estas se encontram, por vezes, longe da racionalização (econômica) excessiva.

É exatamente nesse contexto que está inserido este trabalho, que procura, pela aplicação de um questionário a um grupo de analistas contábil-financeiros, identificar a existência do uso de heurísticas de julgamento e da teoria dos prospectos e, por conseguinte, dos vieses de decisão. A maior contribuição está exatamente no público-alvo do questionário: os analistas contábil-financeiros, pois os autores não encontraram nenhum trabalho que tivesse como respondentes pessoas com este perfil. Ou seja, o enfoque dá continuidade aos vários trabalhos já publicados nas áreas de Finanças e Contabilidade Comportamentais, seguindo a linha de ter como respondentes pessoas com um perfil menos sujeito, a princípio, ao uso das heurísticas de julgamento e da teoria dos prospectos.

\section{Metodologia da Pesquisa}

Esta pesquisa pode ser caracterizada, segundo Vergara (2007), como sendo 
descritiva, pois se procura, pela aplicação de um questionário estruturado e não disfarçado aos respondentes que fazem parte da amostra, expor características a respeito do impacto do uso das heurísticas de julgamento e da teoria dos prospectos, por meio dos vieses de decisão, no processo decisório.

O processo de amostragem é não probabilístico, pois se parte de um universo naturalmente restrito, visto que a escolha dos respondentes que fizeram parte da amostra se deu por conveniência dos pesquisadores, utilizando suas redes de conhecimento. Isso traz algumas limitações de inferência, mas não invalida os resultados da pesquisa, já que o objetivo é buscar um entendimento sobre os aspectos cognitivos do processo decisório.

Para obtenção dos dados, utilizou-se um questionário com oito perguntas fechadas, nas quais os analistas eram convidados a tomar uma decisão ou emitir uma opinião acerca dos aspectos abordados em cada uma das questões. Foram feitos dois tipos de questionários, por conta da necessidade de verificar os vieses relativos ao enquadramento das escolhas. As questões utilizadas para montagem do questionário foram adaptadas dos estudos de Ávila e Costa (1996) e de Bazerman (2001). Além disso, algumas questões preliminares ajudaram a compreender as características dos respondentes da amostra, que foi formada por 91 analistas contábil-financeiros.

Para análise das respostas, foram feitas contagens de frequência para cada opção de cada pergunta e feita uma comparação entre uma resposta racionalmente esperada e uma resposta prevista pela teoria apresentada. Em relação às questões 01 e 06, que levaram a pesquisa a ter dois tipos de questionários, decidiu-se testar as seguintes hipóteses, para cada pergunta, com base em um teste de duas amostras para proporções ao nível de $5 \%$ (STEVENSON, 1981):

- H0: A proporção de escolha da opção A (ou B) nos dois tipos de questionário será a mesma.

- H1: A proporção de escolha da opção A (ou B) no questionário tipo I é diferente da proporção no questionário tipo II.

Por fim, para uma melhor visão do perfil dos respondentes em relação às Heurísticas de Julgamento e à Teoria Prospectiva, aplicou-se uma Análise de Cluster ou Conglomerados para os questionários completos, considerando todas as perguntas exceto as 01 e 06 , por já terem sido objeto de uma outra análise. Nesta análise, as respostas de cada analista para cada pergunta foi transformada em uma variável binária do tipo 01 ou 02 , sendo 01 para os casos de uma resposta não afetada pelos vieses de decisão e 02 para aquelas afetadas por estes. Cabe ressaltar que para esta análise foram desconsiderados os questionários incompletos, num total de oito respondentes eliminados. 
A Análise de Cluster ou Conglomerados é, segundo Hair et al. (2005), uma técnica analítica que pode ser usada para definir grupos significativos de respondentes. Um de seus objetivos específicos é agrupar respondentes que possuam características similares em função das respostas obtidas. Com isso, consegue-se identificar grupos de respondentes que se comportam internamente de maneira uniforme, e externamente, de maneira diferente. Em outras palavras, os respondentes, em cada conglomerado, tendem a ser semelhantes entre si, mas diferentes dos respondentes em outros grupos. Na análise de conglomerados não há qualquer informação a priori sobre a composição do grupo. Na verdade, este é definido pelas próprias características dos respondentes, de modo a resultar em grupos com alta homogeneidade interna (dentro dos grupos) e alta heterogeneidade externa (entre os grupos).

De acordo com Oliveira (2007), para executar uma Análise de Cluster ou de Conglomerados no SPSS, deve-se primeiramente definir os dados e sua estrutura. Tendo os dados para a análise, deve-se escolher o método de aglomeração. No caso deste trabalho, foi utilizado o método Two Step Cluster, que determina automaticamente o número ótimo de clusters a serem formados e pode ser utilizado quando da existência de variáveis categóricas e/ou contínuas. Seus pressupostos são de variáveis independentes e uma distribuição multinomial para variáveis categóricas (que é o caso da análise aqui conduzida).

Como Distance Measure foi utilizado o Método Log-Likelihood e como Clustering Criterion, para determinar como o algoritmo vai escolher automaticamente o número ótimo de clusters, o Schwarz's Bayesian Information Criterion (BIC). A partir daí, estão os respondentes agrupados nos grupos definidos pelo método e, então, pode-se buscar as características que internamente os aproximam e externamente diferenciam os grupos.

Cabe ressaltar, ainda, que, no caso da presente pesquisa, há todas as variáveis utilizadas para a Análise de Cluster definidas como nominais ou categóricas, já que são variáveis dicotômicas. Além disso, para análise da importância das variáveis na formação dos clusters, definiu-se um teste de significância para estas por meio do Pearson Chi-Square Test, com um nível de significância de 95 $\%$. Este define se a variável (viés) é representativa dentro do grupo para sua formação, ou seja, o teste classifica a importância de cada variável em cada Cluster pela comparação entre as frequências esperada (obtidas na amostra completa) e real (no grupo).

A pesquisa de campo foi realizada no período de janeiro de 2007 a fevereiro de 2008, envolvendo analistas contábil-financeiros, cujas empresas estão localizadas na cidade do Rio de Janeiro. Os questionários foram distribuídos pessoalmente ou por e-mail, e os respondentes marcavam uma data para o retorno.

A amostra que foi formada por 91 respondentes, que responderam 40 
questionários do tipo I e 51 do tipo II, contou com 56 analistas do sexo masculino, 34 do sexo feminino e um não respondente. Quanto à formação, verificou-se que 37 analistas eram formados em Ciências Contábeis, 24 em Administração, 13 em Economia, 13 em Engenharia, um em Secretariado Executivo Trilíngüe, dois com formação dupla em Ciências Contábeis e Economia e um com formação em Ciências Contábeis e Administração. O tempo médio de término da graduação foi em torno de 10 anos. Além disso, na amostra, há 39 analistas com $M B A$ ou Pós-Graduação Lato sensu, 22 mestres e 2 que possuem título de doutor. A idade média dos respondentes foi de aproximadamente 34 anos, com um tempo médio de ocupação da função de analista contábil-financeiro de 7 anos.

\section{Apresentação e Análise dos Resultados}

Neste item, analisam-se as oito perguntas relativas ao processo decisório. Algumas questões serão analisadas em conjunto para que se possa verificar o impacto dos vieses de decisão contidos no questionário.

A primeira análise é feita em relação às questões 01 e 06 do questionário. O objetivo destas questões era trabalhar o princípio da invariância, ou seja, se as alternativas são as mesmas, a decisão não deveria se alterar. Não é o objetivo discutir qual é efetivamente a melhor opção, mas mostrar que uma simples manipulação na forma de apresentar as alternativas pode levar os decisores a mudanças de comportamento. Para isso, construiu-se questionários (tipo I e II) que diferenciavam entre si pela existência de dois enunciados distintos para cada questão, como se verifica nos enunciados que mostram a lógica da construção desse raciocínio. A seguir, a descrição de cada uma destas.

Na questão 01, tem-se o tipo I de questionário com as alternativas descritas de forma positiva (poupar), enquanto que no tipo II estão descritas negativamente (prejuízo). Já para a questão 06, é fácil notar que, no primeiro tipo, o plano A é descrito de maneira negativa, enquanto, no segundo tipo, é descrito de maneira positiva, mas, em ambos os casos, o plano A é o mesmo em termos de resultados. O mesmo vale para o plano B.

Nesta pesquisa, para a questão 01 , verificou-se, no questionário do tipo I, que $52 \%$ dos respondentes optaram pela alternativa $\mathrm{A}$, e $48 \%$ optaram pela alternativa $\mathrm{B}$; já no tipo II, 53\% optaram pela alternativa $\mathrm{A}$, e $47 \%$, pela alternativa B. Isso nos leva a concluir que os decisores não se deixaram afetar por este viés, já que o teste aplicado não mostrou diferença estatisticamente relevante nas proporções de cada tipo de questionário. Assim, o fato de apresentar as alternativas de maneira diferente não foi capaz, neste caso, de fazer com que os respondentes sistematicamente contrariassem o princípio da invariância.

Um resultado importante para a análise desta questão é que esta não está 
em consonância com a teoria, que diz que a forma pela qual o problema é "enquadrado" ou apresentado pode alterar drasticamente o ponto neutro percebido da questão. Ou seja, se o problema for enquadrado em termos de perdas (atributos negativos das alternativas), a posição de ganhos passa a ser a referência e o que leva a um comportamento de propensão ao risco. No entanto, se o problema for enquadrado em termos de ganhos (atributos positivos das alternativas), a posição de perdas passa a ser a referência e leva a um comportamento de aversão ou menos propensão ao risco.

\section{Quadro 2: Questões 01 e 06}

1) O responsável pelas questões jurídicas de sua empresa, vem adiando uma das mais cruciais recomendações de toda a história da organização. Você está enfrentando uma ação coletiva impetrada por um grupo de consumidores. Embora você acredite ser inocente, existe a percepção de que o juizado pode não adotar esse mesmo ponto de vista. A expectativa é de que a empresa venha a incorrer em prejuízo de $\mathrm{R} \$$ $50.000,00$ caso perca a ação nos tribunais. A previsão do responsável pela área jurídica é de que seja de $50 \%$ a probabilidade de que a empresa não vença o caso. Mas você tem a opção de selar um acordo extrajudicial através do pagamento de $\mathrm{R} \$ 25.000,00$ às partes prejudicadas. Este caso vem sendo estudado pela área jurídica a mais de seis meses e parece que está na hora de você tomar uma decisão. Qual seria a sua decisão, dentre as opções abaixo:

Tipo I:

A. ( ) Fazer um acordo extrajudicial e poupar $\mathrm{R} \$ 25.000,00$ que poderiam ser perdidos nos tribunais.

B. ( ) Ir aos tribunais esperando uma probabilidade de $50 \%$ de poupar $\mathrm{R} \$ 50.000,00$.

Tipo II:

A. ( ) Fazer um acordo extrajudicial e aceitar um prejuízo certo de $\mathrm{R} \$ 25.000,00$.

B. ( ) Ir aos tribunais esperando uma probabilidade de $50 \%$ de um prejuízo de $\mathrm{R} \$ 50.000,00$.

6) Uma empresa de grande porte foi atingida recentemente por uma série de dificuldades econômicas e parece que será obrigada a fechar três de suas fábricas,demitindo 6.000 empregados. O Vice Presidente de Produção tem investigado alternativas para evitar a crise e desenvolveu dois planos alternativos. Em relação a cada plano ele avalia o seguinte:

Tipo I:

Plano A: Este plano, se adotado, fecha duas das 3 fábricas e demite 4.000 empregados.

Plano B: Este plano, se adotado, implica em $2 / 3$ de probabilidade de que as três fábricas serão fechadas, com perda dos 6.000 empregos, e 1/3 de probabilidade de que as três fábricas serão salvas, e conseqüentemente com os 6.000 empregos mantidos.

Tipo II:

Plano A: Este plano, se adotado, salva uma das 3 fábricas e 2.000 empregados.

Plano B: Este plano, se adotado, implica em $1 / 3$ de probabilidade de que as três fábricas serão salvas, com 6.000 empregos mantidos, e $2 / 3$ de probabilidade de que não se salve nenhuma fábrica e conseqüentemente nenhum emprego.

O que você escolheria?

A. ( ) Plano A

B. ( ) Plano B

Fonte: Elaborado pelos autores.

Nota-se que nessa questão isso não acontece. Tanto no tipo I quanto no tipo II não existe uma preferência declarada pela opção de menor propensão ao risco (A) e nem pela opção de maior propensão ao risco (B), respectivamente. Percebe-se, então, que nesta questão o estudo empírico não confirma o comportamento preconizado pela Teoria Prospectiva. 
Da mesma forma para questão 06 , dentre os analistas que receberam 0 primeiro tipo de questionário (tipo I), 14 escolheram a alternativa $\mathrm{A}(35 \%)$, e 26, a alternativa $B(65 \%)$. Com relação aos analistas que receberam o segundo tipo de questionário (tipo II), 40 escolheram a alternativa A (79\%), e 11, a alternativa B (21\%). Isso mostra que a manipulação da maneira de apresentar as alternativas, na questão 06, levou a uma diferença entre as respostas dos grupos que foram escolhidos de maneira totalmente aleatória. Essa diferença de proporções entre uma mesma opção nos 2 tipos de questionário se mostrou estatisticamente significativa $(\alpha=5 \%)$.

Para a questão 06, percebe-se que a forma pela qual o problema é "enquadrado" ou apresentado altera drasticamente o ponto neutro percebido da questão. No tipo I, existe uma preferência declarada pela opção B (maior propensão ao risco), enquanto no tipo II há uma preferência declarada pela opção A (menor propensão ao risco).

A sétima questão procura confirmar este mesmo aspecto da Teoria Prospectiva, porém de uma forma diferente. Nesta questão, o respondente é levado a escolher uma das opções em que, no item A, elas são apresentadas de forma positiva em termos de ganho, e, no item B, são apresentadas de forma negativa em termos de perda.

O par de opção a no item A e b no item B mostra a influência da Teoria Prospectiva sobre a tomada de decisão, já que, quando o problema foi enquadrado sob a forma de ganhos, o respondente optou pela opção menos arriscada e, quando apresentado sob a forma de perda, escolheu a alternativa mais propensa ao risco. Observa-se que 52 respondentes escolheram essa combinação, o que nos leva a concluir, que $57 \%$ dos analistas sofreram com esse viés de decisão.

\section{Quadro 3: Questão 07 A e B}

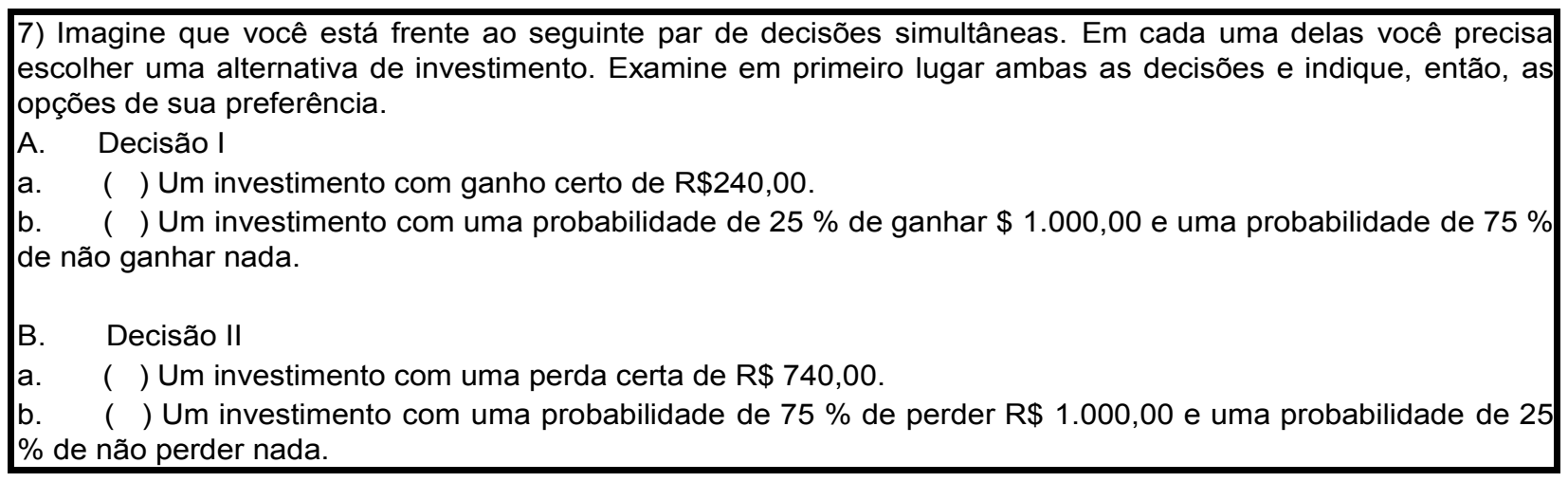

Fonte: Elaborado pelos autores.

Na oitava pergunta do questionário, a intenção era observar a problemática das probabilidades de eventos independentes, ou seja, a condição de que a probabilidade de cada evento independente é necessariamente maior que a pro- 
babilidade de acontecimento de todos estes juntos. Esse é um viés característico da heurística da representatividade que leva a uma distorção bastante comum e sistemática do comportamento decisório, a falácia da conjunção.

Esse viés também pode operar em uma base de maior disponibilidade, ou seja, a conjunção pode criar associações mais intuitivas com eventos, atos ou pessoas vívidas do que um componente dela. Isso resultará numa maior percepção, incorreta, esta como mais provável do que o componente.

\section{Quadro 4: Questão 08}

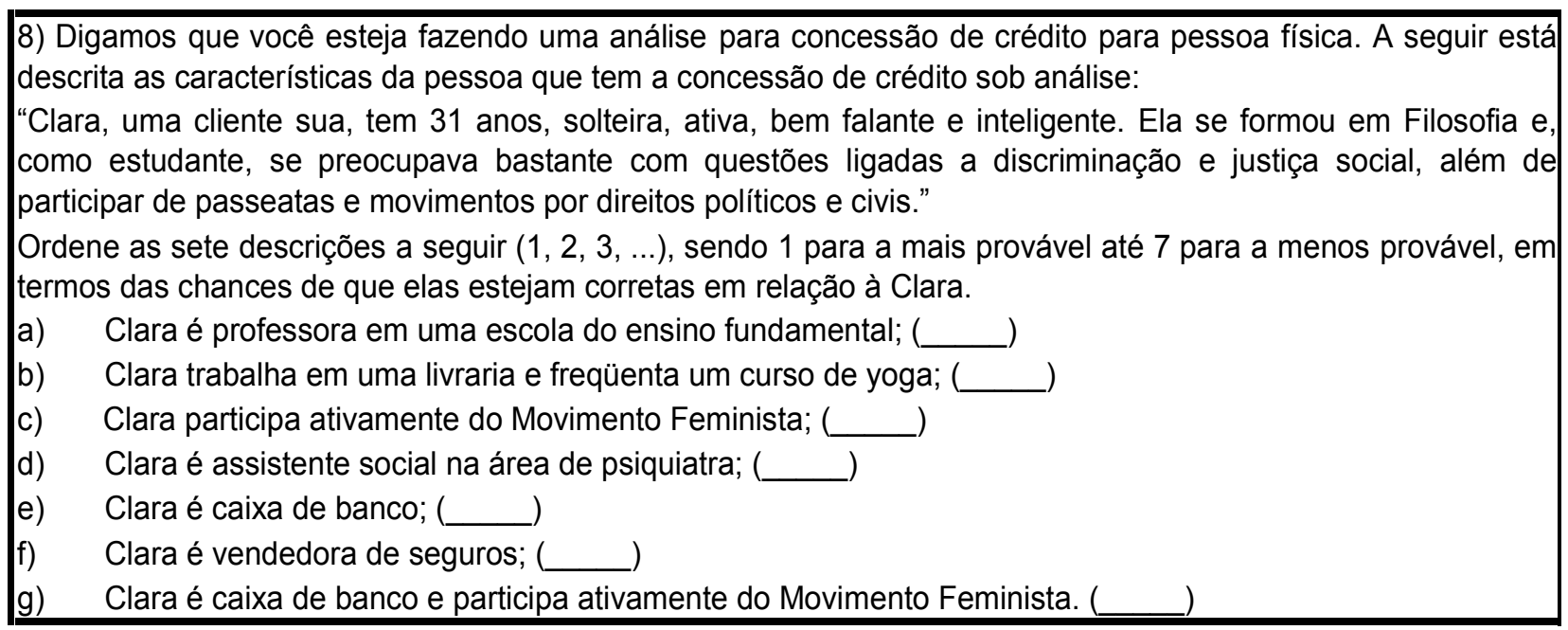

Fonte: Elaborado pelos autores.

Nesta oitava questão, das sete alternativas de respostas propostas, somente algumas eram importantes para o nosso estudo, as demais se prestaram ao papel de coadjuvantes. As importantes para o estudo eram: c; e; g.

Nesta questão, apenas 23 respondentes não inverteram a ordem entre os itens c, e e g. Estes colocaram g como menos provável que c e e. Na verdade, qualquer que seja a ordem de preferência das respostas, os itens c e e devem ter maiores chances de ocorrência que o item $\mathrm{g}$, pois este último pressupõe a ocorrência dos dois itens (c e e), e sua probabilidade de ocorrência é o produto das probabilidades desses itens. Tem-se, então, claramente, a falácia da conjunção agindo por meio da heurística da representatividade, pois é a única explicação para que as probabilidades sejam invertidas.

Na questão 03, procura-se observar a questão da heurística da representatividade numa situação gerencial. A resposta "certa" é a opção a, pois, independente do número de clientes com compras a prazo, a probabilidade de compras à vista não é alterada. Porém observa-se que 48 dos respondentes optaram pelos itens $\mathrm{c}$ e d, que representam probabilidades muito maiores que as reais, mas que são representativas na mente do decisor.

A lógica utilizada nesse tipo de viés de decisão é a seguinte: "Se algo tem uma chance em cada cinco de acontecer e nas ultimas quatro vezes não aconteceu, 
Ao trabalhar com problemas como os apresentados nas questões 03 e 04 , as pessoas ignoram a independência de eventos múltiplos aleatórios em virtude de uma melhor aparência de aleatoriedade e, por outras vezes, julgam as taxas de probabilidade como sendo "uniformes". Isso mostra a preocupação pelo equilíbrio de eventos aleatórios, o que pelo contrário faria com que estes deixassem de ser aleatórios.

As questões 02 e 05 são analisadas em conjunto. Cabe ressaltar que, para análise dessas questões, foram desconsiderados quatro questionários que apresentavam problemas em seu preenchimento. $\mathrm{O}$ enunciado delas é apresentado a seguir.

\section{Quadro 7: Questões 02 e 05 A, B e C}

2) Você foi solicitado a dar um parecer sobre a contratação de um seguro anual para um bem da empresa avaliado em $\mathrm{R} \$ 500.000,00$. O que você recomendaria?

A. ( ) Correr o risco, com probabilidade de $0,16 \%$, de perder o bem de $\mathrm{R} \$ 500.000,00$.

B. ( ) Pagar um prêmio de seguro de $\mathrm{R} \$ 1.000,00$ para não correr este risco.

5) Você está analisando dois novos negócios para sua empresa. Para facilitar você resolveu estudar a probabilidade de ocorrência de certos resultados para estes negócios. Cada item abaixo representa um par de resultados esperados para os dois negócios sob análise. Você deve, portanto, escolher de cada par qual a sua opção, ou seja, qual negócio você prefere.

A. Você prefere:

A. ( ) Um negócio que tenha uma probabilidade de $25 \%$ de ganhar $\mathrm{R} \$ 30,00$.

B. ( ) Ou um negócio que tenha uma probabilidade de $20 \%$ de ganhar $\mathrm{R} \$ 45,00$.

B. Você prefere:

A. ( ) Um negócio que gere uma perda $\mathrm{R} \$ 500.000,00$, com $0,16 \%$ de chance.

B. ( ) Ou um negócio que gere uma perda certa de $\mathrm{R} \$ 1.000,00$.

C. Você prefere:

A. ( ) Um negócio com ganho certo de $\mathrm{R} \$ 30,00$

B. ( ) Ou um negócio com uma probabilidade de $80 \%$ de ganhar $\mathrm{R} \$ 45,00$.

D. Você prefere:

A. ( ) Um negócio que numa primeira fase de negociação tem uma probabilidade de $75 \%$ de terminar a negociação sem ganhar nada e $25 \%$ de prosseguir para uma segunda fase em que se tem um ganho certo de $\mathrm{R} \$ 30,00$.

B. ( ) Ou um negócio que numa primeira fase de negociação tem uma probabilidade de $75 \%$ de terminar a negociação sem ganhar nada e $25 \%$ de prosseguir para uma segunda fase em que se tem uma probabilidade de $80 \%$ de ganhar $\mathrm{R} \$ 45,00$.

Fonte: Elaborado pelos autores.

A análise dessas questões nos remete às decisões afetadas pela PseudoCerteza e Pseudo-Incerteza Enquadradas nas Escolhas, em que a percepção de certeza (probabilidade zero ou um) pode ser facilmente manipulada. Esses efeitos levam à inconsistências de julgamento. No caso do efeito certeza, estamos mais aptos a ficar interessados na redução da probabilidade de eventos certos do que de eventos incertos. Sob o efeito da Pseudo-Certeza, estamos mais inclinados a favorecer opções que nos assegurem a certeza do que aquelas que apenas reduzem a incerteza. 
Numa primeira análise, compararam-se as respostas obtidas nos itens 5A e 5C. Essas duas questões são semelhantes, tendo como única diferença o fato de as probabilidades da questão 5C estarem divididas por 4 na questão 5A. Isso quer dizer que, independente da discussão quanto à preferência em relação ao risco, ou seja, propensão ou aversão, os decisores deveriam escolher os pares de respostas aa ou bb. Observa-se que 26 analistas optaram por b em $5 \mathrm{~A}$ e por a em 5C. A escolha deste par de opções é o que mostra o comportamento influenciado pelo efeito certeza, ou seja, escolhem na primeira questão a opção de maior valor esperado, mas, quando se coloca uma certeza, são levados a escolher a de menor valor esperado (por conta da certeza gerada). Mais uma vez o objetivo não é discutir qual a melhor escolha, até porque isso implicaria o perfil de risco de cada decisor, mas mostrar que, de maneira, no mínimo, pouco racional, as pessoas possuem comportamentos de aversão e de propensão ao risco quando colocadas frente as questões.

Uma análise combinada entre as questões 5A e 5D nos mostra a importância de que as pessoas dão à certeza, pois, nessas questões, pode-se ver o efeito do que denomina-se como pseudo-certeza. As duas questões são iguais, porém na questão 5D divide-se a probabilidade de cada item em duas etapas, que concorrem para dois caminhos possíveis de igual probabilidade aos itens da questão 5A. O par b no item $5 \mathrm{~A}$ e a no item 5D, escolhido por 19 pessoas, mostra o comportamento influenciado pelo efeito da pseudo-certeza, pois esses analistas são influenciadas por uma manipulação da certeza criada pela divisão da decisão em duas fases.

Por fim, da analise das questões 02 e 5B, verificam-se problemas de Enquadramento do Pagamento de Prêmios versus a Aceitação de Perdas Certas. Um prêmio de seguro consiste na perda certa (o prêmio) que se aceita em troca da redução de uma pequena probabilidade de uma grande perda.

Segundo Bazerman (2001), vários estudos mostram que uma perda certa fica mais interessante quando enquadrada como sendo um prêmio de seguro, do que quando enquadrada como prejuízo financeiro. De acordo com Andrade et al. (2007), isso pode ser explicado pela Teoria dos Prospectos, que sugere que, na condição de prejuízo financeiro, as pessoas usam o status quo como ponto de referência. Ao contrário, na condição de prêmio de seguro, o ponto de referência já incorpora o prejuízo correspondente ao prêmio.

Esse estudo sugere que, independente da discussão se o preço do seguro é justo ou não, é mais provável que as pessoas aceitem uma perda certa se esta for encarada como seguro do que se for um prejuízo monetário certo. Isso porque, quando se analisa as questões 02 e 5B, se verifica que 74 respondentes preferem fazer o seguro do que correr o risco de perder o bem. Destes, que optaram pela alternativa b na questão $02,31,1 \%$ (23 analistas) preferem correr o risco de perder R\$ 500.000,00 com 0,16 \% de chance (opção a na questão 5B). Vale ressaltar 
que nove respondentes preferem correr o risco em ambas as situações, ou seja, a princípio devem julgar injusto o valor do prêmio de seguro.

Por fim, a Análise de Cluster ou de Conglomerados, que foi feito com base nos 83 respondentes com questionários completos, aponta para sete grupos e para duas variáveis (vieses) como mais importantes na formação (discriminação) dos grupos: concepção errônea do acaso (questão 03) e decisões afetadas pelo enquadramento dos resultados (questão 07). Os principais resultados, em relação aos vieses de decisão, podem ser descritos da seguinte maneira:

- Grupo 01: Tem como variáveis relevantes na diferenciação em relação aos outros grupos a falácia da conjunção (questão 08) e a concepção errônea do acaso (questão 03). É formado por 13 respondentes $(15,7$ \%) que são pouco afetados pela maioria dos vieses. Na maioria dos casos, nenhum dos respondentes deste grupo é impactado pelo viés recorrente à análise. Isso só não acontece com cinco respondentes no viés das decisões afetadas pelo enquadramento dos resultados (questão 07), três pelo problema de independência entre eventos múltiplos aleatórios (questão 04), um para o efeito pseudo-certeza (questão 5A-5D) e um para a falácia da conjunção (questão 08).

- Grupo 02: Também tem como variáveis relevantes na diferenciação em relação aos outros grupos a falácia da conjunção (questão 08) e a concepção errônea do acaso (questão 03). É formado por oito respondentes (9,6 \%) que também são, de maneira geral, pouco impactados pelos vieses. Porém, chama atenção o fato de que $100 \%$ dos respondentes deste grupo são afetados pelo viés da concepção errônea do acaso (questão 03), e apenas um não é impactado pelo viés das decisões afetadas pelo enquadramento dos resultados (questão 07).

- Grupo 03: Tem como variáveis relevantes para a formação dos clusters os vieses das decisões afetadas pelo enquadramento dos resultados (questão 07) e da independência entre eventos múltiplos aleatórios (questão 04). É formado por 18 analistas $(21,8 \%)$ impactados pelos vieses das decisões afetadas pelo enquadramento dos resultados (questão 07) e da falácia da conjunção (questão 08), ambos com $100 \%$ dos respondentes. Além disso, é um grupo onde nenhum dos respondentes é impactado pelos vieses da independência entre eventos múltiplos aleatórios (questão 04) e do efeito pseudo-certeza (questão 5A-5D). Em relação aos outros vieses, percebe-se que poucos são afetados pelos vieses do enquadramento do pagamento de prêmios de seguros versus a aceitação de perdas certas (questão 02-5B) e do efeito certeza (questão 5A-5C), e que existe um equilíbrio no que diz respeito ao impacto do viés da concepção errônea do acaso (questão 03).

- Grupo 04: Tem como variáveis relevantes na formação dos grupos os vieses das decisões afetadas pelo enquadramento dos resultados (questão 07) e da concepção errônea do acaso (questão 03). Neste grupo, com 10 respondentes $(12,0$ 
\%)aa, todos são afetados pelos vieses da concepção errônea do acaso (questão 03) e da falácia da conjunção (questão 08). Destaca-se que nenhum dos respondentes deste grupo é impactado pelos vieses das decisões afetadas pelo enquadramento dos resultados (questão 07), do efeito pseudo-certeza (questão 5A-5D) e do efeito certeza (questão 5A-5C). Em relação aos outros vieses, percebe-se que poucos analistas são impactados.

- Grupo 05: Neste grupo com nove respondentes (10,8\%), existem as variáveis enquadramento do pagamento de prêmios de seguros versus a aceitação de perdas certas (questão 02-5D), concepção errônea do acaso (questão 03) e decisões afetadas pelo enquadramento dos resultados (questão 07) como relevantes na formação do cluster. Neste, a maioria dos respondentes é afetada pelos vieses do enquadramento do pagamento de prêmios de seguros versus a aceitação de perdas certas (questão 02-5B), do efeito certeza (questão 5A-5C) e da falácia da conjunção (questão 08). Percebe-se, ainda, que poucos destes analistas se deixam levar pelos vieses das decisões afetadas pelo enquadramento dos resultados (questão 07) e da independência entre eventos múltiplos aleatórios (questão 04), e que nenhum é afetado pela concepção errônea do acaso (questão 03).

- Grupo 06: Apresenta como variáveis relevantes os vieses da independência entre eventos múltiplos aleatórios (questão 04) e do enquadramento do pagamento de prêmios de seguros versus a aceitação de perdas certas (questão 02-5B). Neste grupo, todos os 15 respondentes $(18,1 \%)$ são afetados pelo viés de independência entre eventos múltiplos aleatórios (questão 04), e a maioria é impactada pela falácia da conjunção (questão 08). Destaca-se que nenhum dos analistas deste grupo é afetado pelo viés do efeito certeza (questão 5A-5C), e que poucos foram afetados pelo efeito pseudo-certeza (questão 5A-5D). Em relação aos outros vieses, encontra-se equilíbrio entre o número de respondentes impactados e não impactados.

- Grupo 07: Tem como variáveis relevantes o efeito pseudo-certeza (questão $5 \mathrm{~A}-5 \mathrm{D}$ ) e o efeito certeza (questão 5A-5C). Formado por 10 respondentes $(12,0 \%)$ que são afetados por praticamente todos os vieses, exceto em relação ao enquadramento do pagamento de prêmios de seguros versus a aceitação de perdas certas (questão 02-5B), onde nenhum dos respondentes foi impactado. Chama atenção a situação em relação aos vieses do efeito certeza (questão 5A-5C), do efeito pseudo-certeza (questão 5A-5D) e da falácia da conjunção (questão 08), onde $100 \%$ dos respondentes do grupo são afetados.

Para complementar a análise feita com os vieses, buscaram-se informações adicionais sobre os clusters nas variáveis de caracterização dos respondentes. Com relação ao gênero, percebeu-se que a proporção de mulheres no grupo 07 era completamente diferente dos outros grupos. Na amostra como um todo e nos outros grupos, tem-se aproximadamente $65 \%$ de homens e $35 \%$ de mulheres, mas 
no grupo 07 tem-se uma inversão com apenas $30 \%$ dos respondentes do gênero masculino e $70 \%$ do gênero feminino. Isso pode ser um indício de que existam possíveis diferenças entre gêneros no que diz respeito à racionalidade limitada, já que o grupo 07 é formado pelos analistas mais impactados pelos vieses provenientes do uso das heurísticas de julgamento e da teoria dos prospectos.

Além disso, uma análise em relação à formação na graduação revelou que a maioria dos engenheiros foi alocada nos grupos 01 e 02 , exatamente os menos afetados pelos vieses de decisão. Isso pode estar mostrando que uma formação com menor base quantitativa, que acontece nos outros cursos listados pelos respondentes, pode levar a maiores propensões de impacto pelos vieses de decisão.

Outras duas variáveis foram analisadas para verificar suas relevâncias na discriminação entre os grupos: tempo de atuação como analista contábil-financeiro e tempo de conclusão da graduação. A ideia dessas duas variáveis era servir de proxies de experiência. Foi feito o teste não paramétrico de diferença de médias de Kruskal-Wallis para verificar se em relação a estas duas variáveis existia diferença estatisticamente significativa, ao nível de $95 \%$, entre os grupos. Caso fosse encontrada uma diferença significativa, ter-se-ia um indício de que estas variáveis seriam relevantes na separação dos respondentes nos grupos. Porém, os testes mostraram não haver diferença significativa das médias destas variáveis entre os grupos. Logo, para a amostra pesquisada, a experiência não se mostrou um fator relevante na análise do impacto dos vieses de decisão.

\section{Considerações Finais}

Este artigo teve como objetivo analisar o comportamento decisório de analistas contábil-financeiros, especificamente no que diz respeito ao impacto da racionalidade limitada no processo de julgamento e tomada de decisão.

Pela análise do uso das heurísticas de julgamento e da teoria dos prospectos, observou-se que o fato de apresentar as alternativas de maneira diferente faz com que os analistas contábil-financeiros da amostra sistematicamente contrariem o princípio da invariância. Isso mostra que a manipulação da forma implicou uma mudança, a princípio e racionalmente, não esperada, mas explicada pela Teoria Prospectiva (sensibilidade às perdas diferente da sensibilidade dos ganhos) pelo efeito do enquadramento da informação (efeito framing).

Além disso, mostra-se a influência da Teoria Prospectiva sobre a tomada de decisão, pois, de maneira geral, quando um problema foi enquadrado sobre a forma de ganhos, os respondentes optaram pela opção menos arriscada e, quando apresentada sobre a forma de perda, escolheram entre a alternativa mais propensa ao risco.

Ao comparar esses resultados, em relação à Teoria dos Prospectos, com os 
resultados de outros estudos já conduzidos, pode-se verificar, de maneira geral, que eles ratificam os de Ávila e Costa (1996), Macedo et al. (2007a), Fonte Neto e Carmona (2006), Steiner et al. (1998 e 2000) e de Cardoso et al. (2007). Já em relação à pergunta 01 os resultados do presente estudo confirmam os achados de Macedo et al. (2007b).

Outro aspecto analisado foi a problemática dos eventos independentes. Observou-se o impacto da heurística da representatividade, no que diz respeito ao uso da falácia da conjunção, da concepção errônea do acaso e da tendência a ignorar informações relevantes como, por exemplo, o tamanho do universo das possibilidades que existem no problema. Esses resultados corroboram os achados de Macedo et al. (2007a; 2007b) e Prates e Sobreira (2004).

No que diz respeito aos efeitos Certeza e Pseudo-Certeza, observou-se que alguns dos analistas foram influenciados por uma manipulação da certeza, confirmando os achados de Ávila e Costa (1996). Já em relação ao efeito prêmio de seguro, percebeu-se que algumas pessoas tendem a aceitar melhor as perdas quando são colocadas em termos de prêmios de seguro.

Cabe ressaltar que a abordagem da racionalidade limitada não invalida a busca dos decisores pelo incremento do grau de racionalidade em suas decisões, pois é preciso ter cuidado com os desvios que possam ser provocados pelo uso das heurísticas, mesmo que existam ganhos de tempo ao tomar decisões. Para superar esses problemas, é preciso que o analista contábil-financeiro estabeleça prioridades, obtenha informações relevantes, prossiga metódica e cuidadosamente e tenha consciência heurística da possibilidade de desvios tendenciosos.

Este estudo não teve a intenção de esgotar esta temática, mas apenas dar início a uma linha de pesquisa que aprofunde essa discussão, principalmente com experimentos de campo. Mais ainda, a intenção foi dar início a uma discussão que parece não ter sido ainda bem explorada no Brasil, já que houve dificuldade em encontrar estudos focados na racionalidade limitada de analistas da área contábil-financeira. Daí, tem-se a proposta de continuar este estudo, aprofundando a presente análise com uma amostra maior e aplicando outros experimentos.

\section{Agradecimentos}

Os autores agradecem o apoio do CNPq a esta pesquisa.

\section{Referências}

ÁVILA, M. G.; COSTA, I. S. A. Tomada de Decisão: um teste da Teoria dos Prospectos. In: ENCONTRO DA ASSOCIAÇÃO DE PÓS-GRADUAÇÃO E PESQUISA EM ADMINISTRAÇÃO, 20, 1996, Angra dos Reis/RJ. Anais do 
XX ENANPAD. Angra dos Reis/RJ: ANPAD, 1996. p. 305-321.

AGUIAR A. B.; GUERREIRO R. Processo de persistência e mudança de sistema de contabilidade gerencial: Uma análise sob o paradigma institucional. In: CONGRESSO DEL INSTITUTO INTERNACIONAL DE COSTOS, 10, 2007, Lyon. Anais do X ISEOR. Lyon/ França. ISEOR, 2007, 1 CD.

ANDRADE, R. O. B.; ALYRIO, R. D.; MACEDO, M. A. S. Princípios de Negociação: ferramentas e gestão. 2. ed. São Paulo: Atlas, 2007.

BARREIROS R. F.; PROTIL R. M.; MOREIRA V. R. Caracterização da Natureza do Processo Decisório em Nível Estratégico nas Cooperativas Agroindustriais do Estado do Paraná. In: ENCONTRO DAASSOCIAÇÃO DE PÓS-GRADUAÇÃO E PESQUISA EM ADMINISTRAÇÃO, 29, 2005, Atibaia. Anais do XXIX ENANPAD. Atibaia/SP: ANPAD, 2005. 1 CD.

BAZERMAN, M. Judgment in Managerial Decision Making. New York: Wiley, 2001.

BIRNBERG, J. G.; HOFFMAN, V. B.; MOSER, D. V. Comparing and Contrasting Two New Resources for the Behavioral Accounting Researcher. Behavioral Research in Accounting. v. 10, p. 01-22, 1998.

BRANCO, M. C. Uma Abordagem Institucionalista da Contabilidade. Revista Contabilidade \& Finanças. v. 42, n. 4, p. 104-112, 2006.

CARDOSO, R. L.; OYADOMARI, J. C. T.; MENDONÇA NETO, O. R. O Framing Effect em Ambiente Contábil: uma explicação fundamentada na Teoria dos Modelos Mentais Probabilísticos - TMMP. In: ENCONTRO DAASSOCIAÇÃO DE PÓS-GRADUAÇÃO E PESQUISA EM ADMINISTRAÇÃO, 31, 2007, Rio de Janeiro. Anais do XXXI ENANPAD. Rio de Janeiro: ANPAD, 2007. 1 CD.

CARVALHO, C. A.; VIEIRA M. M. F.; LOPES F. D. Contribuições da perspectiva institucional para análise das organizações. In: ENCONTRO DAASSOCIAÇÃO DE PÓS-GRADUAÇÃO E PESQUISA EM ADMINISTRAÇÃO, 23, 1999, Foz do Iguaçu. Anais do XXIII ENANPAD. Foz do Iguaçu/PR: ANPAD, 1999. 1 CD.

CIARELli, G.; ÁVILA, M. G. A Influência da Mídia e a Heurística da Disponibilidade: Um Estudo Experimental. In: ENCONTRO DA ASSOCIAÇÃO DE PÓS-GRADUAÇÃO E PESQUISA EM ADMINISTRAÇÃO, 29, 2005, Brasília. Anais do XXIX ENANPAD. Brasília: ANPAD, 2005. 1 CD. 
DECOURT R. F.; ACCORSI A. As Finanças Comportamentais e o Processo de Decisão no Mercado Financeiro Brasileiro. In: ENCONTRO DAASSOCIAÇÃO DE PÓS-GRADUAÇÃO E PESQUISA EM ADMINISTRAÇÃO, 29, 2005 , Brasília. Anais do XXIX ENANPAD. Brasília: ANPAD, 2005. 1 CD.

FONTE NETO, J. W.; CARMONA, C. U. M. As finanças comportamentais e o Mercado Acionário Brasileiro: evidências do efeito pessimismo em estudos com regressões EGARCH. In: ENCONTRO DA ASSOCIAÇÃO DE PÓS-GRADUAÇÃO E PESQUISA EM ADMINISTRAÇÃO, 30, 2006, Salvador. Anais do XXX ENANPAD. Salvador: ANPAD, 2006. 1 CD.

GUERREIRO, R.; PEREIRA, C. A.; LOPES A. B. Uma Contribuição ao Entendimento da Estabilidade e da Mudança da Contabilidade Gerencial sob a Ótica da Teoria Institucional. In: ENCONTRO DA ASSOCIAÇÃO DE PÓS-GRADUAÇÃO E PESQUISA EM ADMINISTRAÇÃO, 28, 2004, Curitiba. Anais do XXVIII ENANPAD. Curitiba: ANPAD, 2004. 1 CD.

HAIR, J. F., ANDERSON, R. E., TATHAM, R. L., BLACK, W. C. Análise Multivariada de Dados. Porto Alegre: Bookman, 2005.

HALFELD, M.; TORRES, F. F. L. Finanças Comportamentais: aplicações no contexto brasileiro. Revista de Administração de Empresas. v. 41, n. 2, p. 64$71,2001$.

KAHNEMAN, D. P.; TVERSKY, A. Prospect theory: an analysis of decision under risk. Econometrica. pp. 263-291, March, 1979.

KAHNEMAN, D. P.; SLOVIC, P.; TVERSKY, A. Judgment under Uncertainty: Heuristics and Biases. Cambridge: Cambridge University Press, 1988.

KIMURA, H. Aspectos comportamentais associados às reações do mercado de capitais Revista de Administração de Empresas Eletrônica. v. 2, n. 1, 2003. Disponível em <www.rae.com.br/eletronica>. Acesso em 15 set. 2006.

KIMURA, H.; BASSO, L. F. C. Finanças Comportamentais: investigação do comportamento decisório dos agentes brasileiros. In: ENCONTRO DA ASSOCIAÇÃO DE PÓS-GRADUAÇÃO E PESQUISA EM ADMINISTRAÇÃO, 27, 2003, Atibaia. Anais do XXVII ENANPAD. Atibaia/SP: ANPAD, 2003. 1 CD.

LOUBACK J.; TEIXEIRA M. L. M.; BIDO D. S. Valores Organizacionais e Racionalidades: Uma Visita ao Terceiro Setor. In: ENCONTRO DAASSOCIAÇÃO DE PÓS-GRADUAÇÃO E PESQUISA EM ADMINISTRAÇÃO, 31, 2007, Rio de Janeiro. Anais do XXXI ENANPAD. Rio de Janeiro: ANPAD, 2007. 1 CD. 
LUPPE, M. R.; ANGELO, C. F.; FÁVERO, L. P. L. Decisões de Consumo: a heurística da ancoragem e seus efeitos no julgamento. In: ENCONTRO DA ASSOCIAÇÃO DE PÓS-GRADUAÇÃO E PESQUISA EM ADMINISTRAÇÃO, 31, 2007, Rio de Janeiro. Anais do XXXI ENANPAD. Rio de Janeiro: ANPAD, 2007. 1 CD.

MACEDO, M. A. S.; ALYRIO, R. D.; ANDRADE, R. O. B. Análise do Comportamento Decisório: um estudo junto a acadêmicos de administração. Revista Ciências da Administração. v. 9, n. 18, p. 35-55, 2007a.

MACEDO, M. A. S.; FERREIRA, R.; ANDRADE, J. E. A.; ALYRIO, R. D. Processo Decisório Gerencial: um estudo do modelo descritivo de tomada de decisão aplicado a pequenos empreendedores. Revista da Micro e Pequena Empresa. v. 1, n. 1, p. 24-37, 2007 b.

OLIVEIRA, C. A.; ALPERSTEDT, G. D. O lado intuitivo das decisões estratégicas: o caso de uma indústria de papel do planalto serrano catarinense. In: ENCONTRO DA ASSOCIAÇÃO DE PÓS-GRADUAÇÃO E PESQUISA EM ADMINISTRAÇÃO, 27, 2003, Atibaia. Anais do XXVII ENANPAD. Atibaia/ SP: ANPAD, 2003. 1 CD.

OLIVEIRA, F. E. M. SPSS Básico para Análise de Dados. Rio de Janeiro: Ciência Moderna, 2007.

PRATES, C. E. M.; SOBREIRA, R. Processo Decisório em Ambientes organizacionais: o instrumento da 'Representatividade'. In: ENCONTRO DAASSOCIAÇÃO DE PÓS-GRADUAÇÃO E PESQUISA EM ADMINISTRAÇÃO, 28, 2004, Curitiba. Anais do XXVIII ENANPAD. Curitiba/ PR: ANPAD, 2004. 1 CD.

PRESUTTI Jr., A. H. Anchor and Adjustment Heuristic Effect on Audit Judgement. Managerial Auditing Journal. v. 10, n. 9, p. 13-21, 1995.

SIMON, H. A. A behavioral model of rational choice. Quarterly Journal of Economics. v. 69, p. 99-118, 1955.

SIMON, H. A. Models of Man. New York: John Wiley and Sons, 1957.

SHLEIFER, A. Inefficient Market: an introduction to behavioral finance. New York: Oxford University Press, 2000.

SOUZA, A. A.; PASSOLONGO, C.; SOUZA, N. C.; ARAUJO, A. C. N. Avaliação da Satisfação dos Usuários de Sistemas de Informações Financeiras. In: CONGRESSO USP DE CONTROLADORIA E CONTABILIDADE, 6, 2006, 
São Paulo/SP. Anais do VI Congresso USP de Controladoria e Contabilidade. São Paulo: FEA/USP, 2006. 1 CD.

STEINER NETO, P. J.; SILVA, L. G.; GRAMMS, L. C.; MARCELINO, E.; PRADO, P. A Teoria dos Prospectos Revisitada: a influência dos beneficiários da decisão. In: ENCONTRO DA ASSOCIAÇÃO DE PÓS-GRADUAÇÃO E PESQUISA EM ADMINISTRAÇÃO, 22, 1998, Foz do Iguaçu/PR. Anais do XXII ENANPAD. Foz do Iguaçu/PR: ANPAD, 1998. 1 CD.

STEINER NETO, P. J.; GUARIDO FILHO, E. R.; OLIVEIRA, P. T. Tomada de Decisão em Instituições Financeiras: consistência entre domínios e abordagens. In: ENCONTRO DA ASSOCIAÇÃO DE PÓS-GRADUAÇÃO E PESQUISA EM ADMINISTRAÇÃO, 24, 2000, Florianópolis. Anais do XXIV ENANPAD. Florianópolis: ANPAD, 2000. 1 CD.

STEVENSON, W. J. Estatística Aplicada à Administração. São Paulo: Harbra, 1981.

TVERSKY, A.; KAHNEMAN, D. Availability: a heuristic for judging frequency and probability. Cognitive Psychology. v. 5, p. 207-232, 1973.

TVERSKY, A.; KAHNEMAN, D. Judgment under uncertainty: heuristics and biases. Science. v. 185, p. 1124-1131, 1974.

VERGARA, S. C. Projetos e Relatórios de Pesquisa em Administração. 9. ed. São Paulo: Atlas, 2007.

WILLAMS, P. F.; JENKINS, G.; INGRAHAM, L. The Winnowing away of Behavioral Accounting Research in the US: the process for anointing academic elites. Accounting, Organizations and Society. v. 31, p. 783-818, 2006.

YOSHINAGA, C. E. ; OLIVEIRA R. F.; SILVEIRA A. D. M.; BARROS L. A. B. C. Finanças Comportamentais: uma introdução. In: SEMINÁRIOS EM ADMINISTRAÇÃO, 7, 2004, São Paulo. Anais do VII SEMEAD. São Paulo: FEA/USP, 2004. 1 CD. 
